\title{
Arbovirus and seizures
}

\author{
Mingrui Zheng ${ }^{1}$, Shichuo Li ${ }^{2}$, R. Edward Hogan ${ }^{3 *}$ and Meihua Yang ${ }^{3,4^{*}}$
}

\begin{abstract}
The high prevalence and spread of arthropod-borne viruses (arboviruses) make them an important cause of viral encephalitis in humans. Most epidemic viral encephalitides have an etiology associated with arboviruses. Among various arboviruses, the Japanese encephalitis virus, West Nile virus, Zika virus, Dengue virus and Chikungunya virus can induce seizures. Arboviruses of the genus Flavivirus are usually transmitted by mosquitoes and other host animals. These vector-borne pathogens can cause epidemic viral encephalitis. Seizures may not be the major manifestation in these viral encephalitides, but may predict a poor prognosis. In this article, we discuss the relationships between these viruses and seizures from perspectives of clinical characteristics, pathogenesis, prognosis and treatments of each.
\end{abstract}

Keywords: Seizures, Japanese encephalitis, West Nile virus, Zika virus, Dengue virus, Chikungunya virus

\section{Japanese encephalitis virus (JEV) Clinical characteristics}

Japanese encephalitis (JE) is the most common form of arbovirus encephalitis and is related to acute symptomatic seizures, especially in children. JEV is usually transmitted by Culex mosquitoes and has a bird-pig life cycle. Human beings are the dead-end host of the virus. Most infected cases are in developing countries located at Southeast Asia, Western Pacific and Eastern Mediterranean regions.

Seizure is one of the major clinical manifestations of JEV infection, but has varied frequencies of occurrence among different reports. According to a case report in Central Sarawak, Malaysia [1], seizures occurred in 50$80 \%$ of infected patients, more frequently in children than in adults. The epidemiological reports of early seizures often underestimated the incidence, probably due to the poor access to appropriate caregivers and facilities for diagnosis. Early seizures are often detectable only by continuous electroencephalographic monitoring (EEG) [2], which is limited in developing countries compared to developed countries. This results in variable

\footnotetext{
*Correspondence: hoganre@wustl.edu; ymh070916@163.com;

meihua.yang@bjc.org

${ }^{3}$ Department of Neurology, Washington University, St. Louis, MO 63110-1093, USA

Full list of author information is available at the end of the article
}

conclusions for seizure occurrence rate in JEV encephalitis. MRI has revealed thalamic, basal ganglia and brainstem involvement in JE [3]. The clinical manifestations of subtle seizures may appear as eye, mouth or extremity twitching/myoclonus, nystagmus, excessive salivation, or irregular respiration [4]. The EEG patterns of JEV brain infection include isolated discharges, periodic lateralized epileptiform discharges, multiple seizures, continuous seizures, and status epilepticus [5]. In a study conducted in India, seizures occurred in $40 \%$ of JE patients, and generalized tonic-clonic seizures were the most common type in this case series [3].

\section{Neuroimaging findings}

The MRI characteristics of JE patients are bilateral thalamic lesions. These lesions show high signal intensities in $\mathrm{T} 2$ and fluid attenuation inversion recovery (FLAIR) sequences [6] (Fig. 1).

In JE, real-time monitoring of EEG is important for appropriate treatment and enables detection of early seizures. The general EEG findings in JE are a constant pattern of diffuse delta activity, which is likely due to bilateral thalamic involvement [8]. These characteristic EEG findings are very common and do not predict a poor outcome. When seizures occur, patients typically manifest abnormalities including theta and delta coma,

(c) The Author(s). 2020, corrected publication 2020. Open Access This article is licensed under a Creative Commons Attribution 4.0 International License, which permits use, sharing, adaptation, distribution and reproduction in any medium or format, as long as you give appropriate credit to the original author(s) and the source, provide a link to the Creative Commons licence, and indicate if changes were made. The images or other third party material in this article are included in the article's Creative Commons licence, unless indicated otherwise in a credit line to the material. If material is not included in the article's Creative Commons licence and your intended use is not permitted by statutory regulation or exceeds the permitted use, you will need to obtain permission directly from the copyright holder. To view a copy of this licence, visit http://creativecommons.org/ licenses/by/4.0/. 


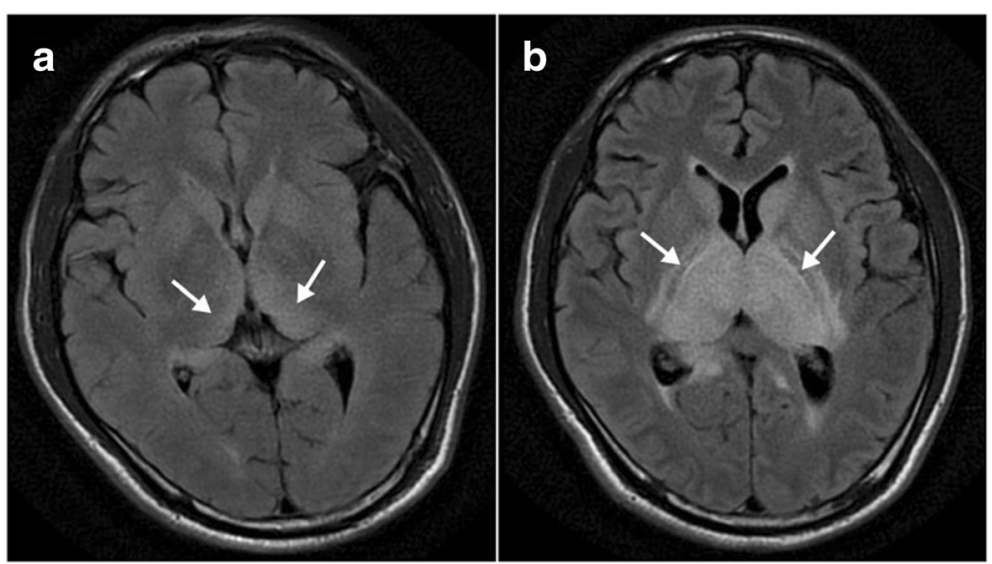

Fig. 1 Characteristic changes on MRI with FLAIR sequence on day 1 (a) and day 5 (b) of JEV patients [7]

burst suppression, an isoelectric pattern, or occasionally alpha coma [4].

\section{Pathogenesis \\ Tropism with the brain}

JEV's neurotropism is a relevant factor of its pathogenesis. Neurotropism is not synonymous with neurovirulence, but they can be associated with each other in some cases. The JEV typically replicates in the skin before it spreads to local lymph nodes. Then it travels to the liver, heart, kidney and other organs before crossing the blood-brain barrier (Fig. 2). To cross the blood-brain barrier, JEV replicates in endothelial cells or inflammatory cells that carry the virus (Fig. 3).

\section{Activated glia}

In mice with central nervous system (CNS) infection with JEV, researchers have observed activation of astrocytes [9]. The activated astrocytes can inhibit the intake of glutamic acid and the synthesis of $\gamma$-aminobutyric acid (GABA), resulting in neuronal hyperexcitability. In addition, inwardly rectifying potassium channels are down-regulated in epilepsy and inflammation. This may make astrocyte unable to balance extracellular $\mathrm{K}+$ concentration $[10,11]$. Further detailed mechanisms remain to be elucidated by more experiments.

Activated microglia are also observed in the CNS. JEV-infected microglia can up-regulate miR-146a, facilitating the expression of miR-146a and the replication of the virus [12]. On the other hand, the levels of IL-1 $\beta$, IL6 , TNF- $\alpha$ and other proinflammatory mediators are significantly elevated during JEV infection. These proinflammatory mediators released by activated microglia can induce neuronal loss [13]. The auto-toxic loop led by microglial activation possibly results in proliferation and formation of microglial nodules, contributing to the pathogenesis of refractory epilepsy. Moreover, microglia also participate in the formation of blood-brain barrier.

In addition, JEV has tropism for neuroblast-derived cells [14], which may be related to the formation of abnormal synapses. The formation of abnormal synaptic connections will result in abnormal discharges [15].

\section{Further information}

Research by Yao et al. showed that the expression of miR-16-1 and heat shock protein 70 was upregulated in astrocytes during the occurrence of epilepsy after JEV infection [16]. Another case report led by $\mathrm{Ma}$ et al. showed that JEV infection can trigger anti-N-methyl- $D$ aspartate receptor encephalitis [17]. This implies an autoimmunity-related mechanism underlying neuronal damage by JEV. However, studies on the specific mechanisms of JEV-induced epilepsy are limited because of its rare occurrence.

\section{Treatments}

Currently, no clinically-approved therapy is available for the treatment of any flavivirus infection [18], but hospitalization for supportive care is generally required [19]. Therefore, complications such as seizures should be diagnosed at an early time for appropriate treatment, and AED treatment is indicated for neonatal seizures, which may be subclinical.

\section{Prognosis}

The prognosis of epilepsy is determined by etiology, severity, site of infection, and certain host factors [20]. Timely and effective control of seizures is an important measure to improve prognosis. Antiepileptic drugs are commonly used to treat epilepsy after infection. Yet, due to the lack of effective treatment of CNS infection, it is difficult to prevent post-encephalitic epilepsy. 


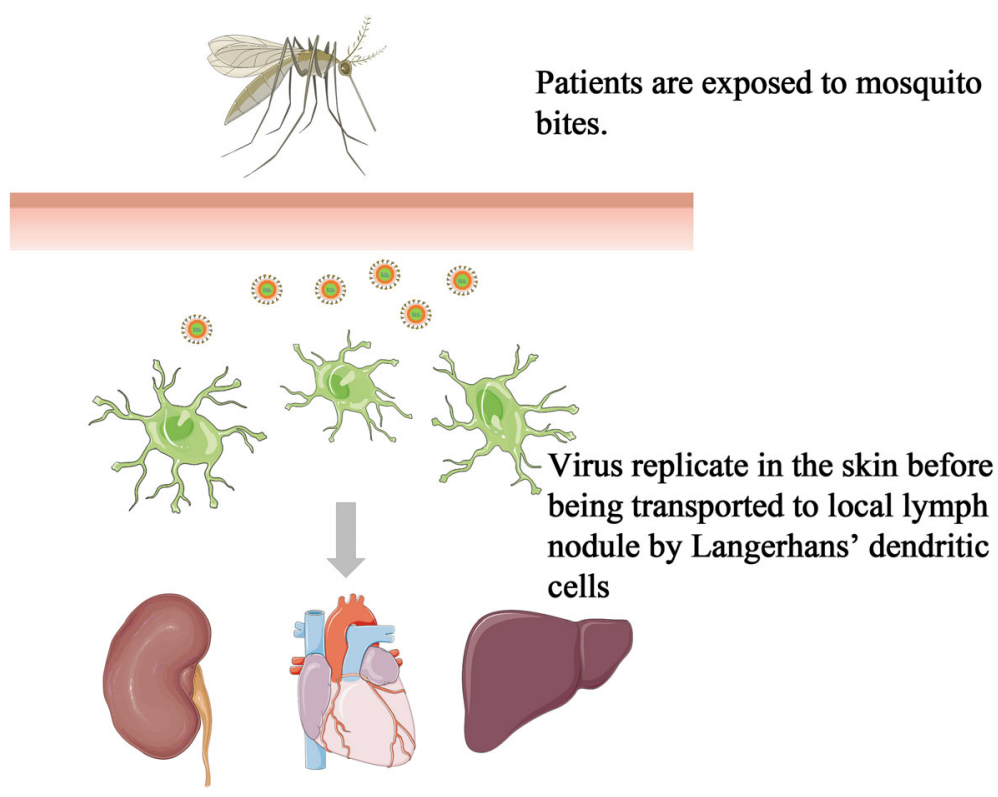

The virus is transported to liver, kidney, heart and other organs before reaching the brain.

Fig. 2 The process of JEV infection in the human body

It is important to note that seizures in JEV infection often indicate a poor prognosis. Around $20 \%$ of patients who survive the acute JEV infection develop long-term seizures. More detailed studies assessing long-term consequences are lacking in epidemic regions. Timely diagnosis and treatment of seizures may reduce the associated damage to the brain and improve the prognosis by preventing increased intracranial pressure, brain herniation and death. As long-term seizures may occur as a result of epileptogenesis due to cortical dysfunction, timely medical treatment is the best choice to find and control early seizures in arbovirus-infected patients.

\section{West Nile virus (WNV)}

WNV is related antigenically to the JE antigenic complex of the Flaviviradae family, so the pathogenesis of WNV infection is very similar to that of JEV. Humans and horses are the dead-end hosts of WNV. Horses are commonly recognized to develop symptomatic infections. Seizures are not a common symptom for WNV

In theory, virus cross the blood-brain barrier by replication in the endothelial cells or in the inflammatory cells that enter the brain parenchyma.

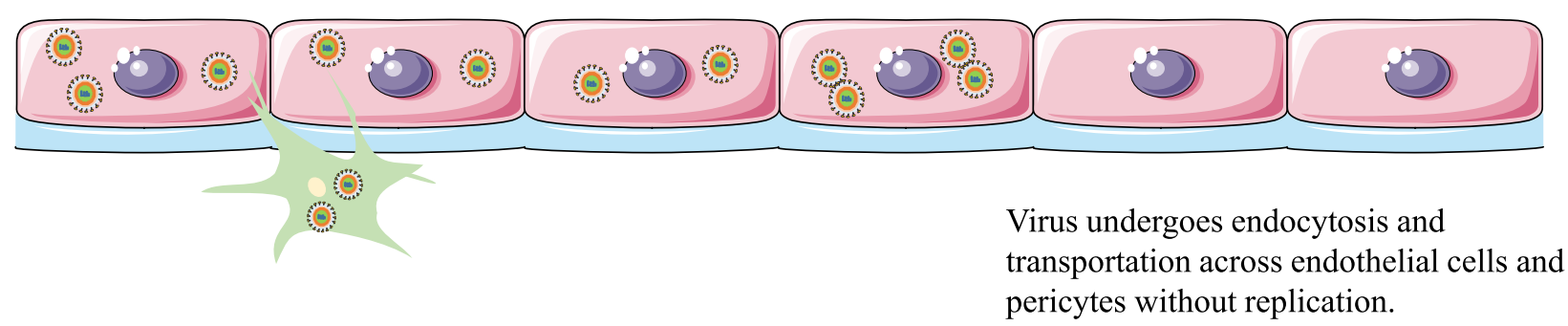

Fig. 3 The process of JEV across the blood-brain barrier 
infection, and their occurrences are also lower than those in JEV. WNV-associated epilepsy is rarely reported. In a report of WNV disease outbreak in Pakistan [21], 15\% of patient with confirmed WNV had seizures. In addition, there are no definitive reports of prognosis of WNV-associated seizures.

\section{Clinical characteristics}

In recent studies, most WNV infections are asymptomatic. Only $20 \%$ of patients manifest some mild symptoms such as flu-like illnesses. Virus entry into the CNS occurs in $<1 \%$ of the symptomatic individuals. However, in horses, the percentage of neurologic symptoms is $10 \%$. Older patients tend to have a higher frequency of severe neurological symptoms and higher mortality. While the incidence varies between series, seizures appear uncommon in West Nile encephalitis and are estimated to occur in 3 to $6 \%$ of patients [22].

\section{MRI}

The most characteristic MRI findings in West Nile encephalitis patients are bilateral signal abnormalities in the basal ganglia and thalami on T2, FLAIR and diffusion-weighted image sequences, indicating possible viral neurotropism for these deep gray structures [23]. However, these findings are not specific, which means that they can also appear in other Flavivirus encephalitides. In fact, MRI is not a sensitive diagnostic tool for West Nile encephalitis because sometimes MRI findings can be normal even in severe cases [24-26].

\section{Pathogenesis}

The frequency of seizures in WNV-infected cases is low, as previously discussed. As mentioned above, WNV entry to the CNS is uncommon and therefore poorly documented, but several possible routes for entry have been proposed: (1) entry through the blood-brain barrier disrupted by TNF- $\alpha$, IL- $1 \beta$ and certain macrophage migration inhibitory factors [27, 28]; (2) entry through choroid plexus epithelial cells [29]; (3) infecting olfactory neurons and spreading via the olfactory bulb [30] (also seen in other flaviviruses); and (4) entry through infected immune cell infiltration into the CNS [30].

\section{Treatments}

Treatment for WNV infection is also mostly supportive. Seizures, although rare, should be appropriately treated to reduce possible complications such as increased intracranial pressure.

\section{Zika virus (ZIKV)}

ZIKV is another member of the flavivirus family. About $80 \%$ of ZIKV infections are asymptomatic. The association with seizures has only been described recently.
Analysis of clinical data shows that ZIKV infection in pregnant women is related to infant congenital microcephaly [31], an extreme consequence with spontaneous epileptic activity developing in 50-60\% of microcephalic babies congenitally infected with ZIKV [32, 33]. Therefore, we discuss in the following the possible relationship between seizures and ZIKV-induced microcephaly.

\section{Clinical characteristics}

ZIKV infection is asymptomatic in three of every four infected patients [34]. Most symptoms are mild and selflimited, and often disappear within a week. The only two exceptions are Guillain-Barré syndrome and microcephaly. Microcephaly is a neurological condition generally associated with severe brain malformations. The increased incidence of microcephaly among children in Brazil has been accounted for by several reasons, including the rise of ZIKV infections, and seizures appear to be a common symptom in ZIKV-induced microcephalic infants.

Although microcephaly does not manifest in all neonates infected by ZIKV in utero, seizures are also observed in neonates without microcephaly [35]. Congenital Zika syndrome (CZS) is a common manifestation in neonatal infection cases. CZS manifests as a consequence of direct neurological insult and severe intracranial volume loss [36]. The inhibited neurogenesis and increased neuronal apoptosis over progenitor cells in CZS result in microcephaly, facial disproportionality, hypertonia, hyper-reflexia and irritability [37, 38]. Hearing and visual loss are also seen in CZS infants [36]. Seizures are the major complication among CZS infants in the first 4 months of life [39].

\section{CT and MRI}

In microcephaly-induced by ZIKV infection, the most common neuroimaging features are calcifications in the junction between cortical and subcortical white matter, which are associated with malformations of cortical development. Additional findings are an enlarged cisterna magna, corpus callosum abnormalities, ventriculomegaly, delayed myelination, and cerebellum and brainstem hypoplasia [40].

\section{Pathogenesis}

Microcephaly is usually divided into two types--primary or congenital microcephaly and secondary or post-natal microcephaly $[41,42]$. The primary microcephaly is usually due to the reduced amount of neurons, while the secondary microcephaly is often due to the decreased dendritic processes and synaptic connections. Both types of microcephaly can develop with seizures.

In cases that do not manifest microcephaly, the pathogenesis is similar to JEV-brain inflammation. In research 
by Nem de Oliveira Souza et al. [43], ZIKV induced spontaneous seizures in young mice, and there was an increased level of proinflammatory cytokines in the placental tissue and neonatal brain, accompanying viral replication.

\section{Treatments}

Neonatal seizures have low response to conventional anticonvulsant drugs [44] and may require multiple antiseizure medications. In murine models, researchers found that early inhibition of TNF- $\alpha$-mediated neuroinflammation may be an effective therapeutic strategy to prevent the development of chronic neurological abnormalities [43]. More importantly, tests for ZIKV infection should be run in early pregnancy or before pregnancy to prevent neonatal CNS malformations and other abnormalities.

\section{Prognosis}

Since most ZIKV infections are asymptomatic, most patients go untreated and have a good prognosis. Severe cases such as neonatal ZIKV infection should receive seizure assessment and appropriate treatment from health care professionals. However, the overall prognosis of severe cases is typically poor.

\section{Dengue virus (DENV)}

DENVs are transmitted by A.aegypti mosquitoes. 75\% of DENV infections are asymptomatic. The major clinical manifestations are systematic signs and symptoms without associated epileptic seizures, with rare exceptions.

\section{Clinical characteristics}

Although seizures and epilepsy are not a common manifestation in a dengue infection, they are more likely to occur if patients develop neurological symptoms. An investigation in Thailand [45] shows that among 1493 children diagnosed with dengue infection, $5.4 \%$ of them developed neurological manifestations, including seizures in $67 \%$. In some individual case reports, the patients with severe, fatal dengue fever could have concomitant seizures $[46,47]$.

\section{Pathogenesis}

Similar to JEV, DENV is able to cross the blood-brain barrier and have tropism to the brain. However, it replicates in the CNS, while JEV replicates in the skin where mosquitoes inject JEV. In some neurophathological autopsy studies, DENV and its antigen are found in brain tissues without histological inflammatory features [4852]. This is probably why DENV causes a lower rate of seizure occurrence.

The occurrence rate of DENV neuroinfection remains unknown. It has been shown to occur preferentially in immune- or neurological-immature murine models, yet there are cases of adult patients without any sign of immune system impairment [53].

\section{Chikungunya virus (CHIKV)}

CHIKV was newly discovered in Puerto Rico in May 2014, and is mainly transmitted by mosquitoes of the Aedes genus (A.ageypti and A.albospictus) [54].

\section{Clinical characteristics}

Unlike ZIKV and DENV, most individuals with CHIKV infection are symptomatic. The major symptoms of CHIKV infection are similar to dengue fever. Other manifestations include arthralgias and myalgias, and neurological complications in severe cases. Seizures are a common neurological manifestation in CHIKVinfected children [55-58].

\section{Pathogenesis}

CHIKV has tropism for fibroblasts in the dermis, joint capsules and muscles. Human epithelial and endothelial cells can also be infected by CHIKV [59]. However, CHIKV cannot invade neural tissue or replicate in neurons [60]. There are no related autopsy and histopathological studies, so the target cells of CHIKV in the human brain remain unknown [60]. In experimentally infected mice, the virus preferentially infects astrocytes [61].

\section{Prognosis}

Early seizures can be subtle, so EEG is needed for diagnosis. As a result, hospital care is necessary for patients. However, there are also counterexamples. A report of an outbreak of Chikungunya Virus in 2014 [62] suggested that seizures occurred more frequently in hospitalized patients than non-hospitalized patients.

\section{Treatments}

There is no specific treatment for CHIKV infection.

\section{Discussion}

To treat epilepsy after arbovirus infection effectively, more information on specific mechanisms is needed. Most seizures triggered by arbovirus infection are induced by viral encephalitis. Only neurotropic viruses have abilities to invade, infect and subsequently replicate within the human nervous system. Epilepsy in viral encephalitis is mainly caused by direct cell damage by the virus and secondary inflammatory responses, during which glia and cytokines are active players. The associated damage to the bloodbrain barrier also contributes to seizure occurrence.

Flavivirus nonstructural protein 1 (NS1), which is secreted by related flaviviruses and circulates in the host blood stream [63], triggers tissue-specific vascular 
endothelial dysfunction. In a study led by Puerta-Guardo and colleagues [64], the pathophysiology of each flavivirus is highly related to NS1. NS1 from different flaviviruses alter the human endothelial cell permeability in certain tissues at different degrees. For DENV, NS1 can enhance the endothelial permeability in all tissues so DENV usually causes systemic manifestations. NS1 from JEV and WNV can increase the endothelial permeability in brain tissues, promoting induction of encephalitis. Due to the high relevance between neuroinflammation and seizures as previously discussed, this factor explains why JEV induces seizures in a higher frequency as compared to other flaviviruses. However, why WNV is antigenically similar to JEV while having a much lower rate of neurological symptoms remains unclarified. NS1 from ZIKV has a high concentration in the human placental tissue and developing brain, inducing hyperpermeability of the umbilical vein and brain endothelial cells. This may explain the occurrence of neonatal congenital microcephaly after ZIKV infection during pregnancy.

\section{Further directions}

Given the limited treatment options for flavivirus CNS infections and associated seizures, there is a great need for further research to determine the underlying associated pathophysiological causes. Barriers to research include a lack of suitable animal models for testing CNS arbovirus infections [65]. The relationship between neuroinflammation caused by these viruses and seizures requires further research. Animal models for seizures induced by infection can be established in rabbits, rats and mice. However, these animals often develop acute encephalitis before seizures occur. The unpredictable rate of seizures in animal models is another important barrier for further research. There is still a great need of appropriate animal models for viral infection-induced seizures.

\section{Conclusions}

Flavivirus infections are associated with neurological diseases, including seizures and epilepsy. The type of flavivirus plays an important role in the probability of CNS involvement and associated seizures after viral infection. Appropriate clinical care requires cautions of possible flavivirus infection, as well as involvement of seizures. Specifically, some patients will require appropriate EEG recording to detect seizures. Effective treatment of associated epileptic seizures enables good supportive care and optimal control of CNS-related comorbidities.

\section{Abbreviations}

JEV: Japanese encephalitis virus; EEG: Electroencephalography; CNS: Central nervous system; AEDs: Antiepileptic drugs; WNV: West Nile virus; ZIKV: Zika virus; CZS: Congenital Zika syndrome; DENV: Dengue virus;

CHIVK: Chikungunya virus; NS1: Nonstructural protein 1

\section{Acknowledgements}

Not applicable.

\section{Authors' contributions}

YMH concieved and laid out the entire article frame, ZMR wrote the first draft of the article. LSC, HRE, and YMH helped with revision and

improvements. All authors read and approved the final manuscript.

\section{Funding}

This study was partially supported by the National Natural Science Foundation of China (No 81971219).

Availability of data and materials Not applicable.

Ethics approval and consent to participate

Not applicable.

Consent for publication

Not applicable.

\section{Competing interests}

The authors declare that they have no competing interests.

\section{Author details}

${ }^{1}$ West China School of Basic Medicine and Forensic Medicine, Sichuan University, Chengdu 610041, China. ${ }^{2}$ China Association Against Epilepsy (CAAE), Beijing, China. ${ }^{3}$ Department of Neurology, Washington University, St. Louis, MO 63110-1093, USA. ${ }^{4}$ Epilepsy Centre, Department of Neurosurgery, Xinqiao Hospital, Army Military Medical University, Chongqing 400037, China.

Received: 6 May 2020 Accepted: 4 September 2020

Published online: 28 October 2020

\section{References}

1. Ooi MH, Lewthwaite P, Lai BF, Mohan A, Clear D, Lim L, et al. The epidemiology, clinical features, and long-term prognosis of Japanese encephalitis in Central Sarawak, Malaysia, 1997-2005. Clin Infect Dis. 2008; 47(4):458-68.

2. Misra UK, Tan CT, Kalita J. Viral encephalitis and epilepsy. Epilepsia. 2008;49:13-8.

3. Misra UK, Kalita J. Seizures in encephalitis: predictors and outcome. SeizureEuropean J Epilepsy. 2009;18(8):583-7.

4. Solomon T, Vaughn DW. Pathogenesis and clinical features of Japanese encephalitis and West Nile virus infections. Curr Top Microbiol Immunol. 2002;267:171-94.

5. Solomon T, Dung NM, Kneen R, le TT T, Gainsborough M, Nisalak A, et al. Seizures and raised intracranial pressure in Vietnamese patients with Japanese encephalitis. Brain. 2002;125(Pt 5):1084-93.

6. Misra UK, Kalita J. Overview: Japanese encephalitis. Prog Neurobiol. 2010; 91(2):108-20.

7. Keng LT, Chang LY. Japanese encephalitis. CMAJ. 2018;190(21):E657.

8. Misra UK, Kalita J, Jain SK, Mathur A. Radiological and neurophysiological changes in Japanese encephalitis. J Neurol Neurosurg Psychiatry. 1994; 57(12):1484-7

9. Myint KSA, Gibbons RV, Perng GC, Solomon T. Unravelling the neuropathogenesis of Japanese encephalitis. Trans R Soc Trop Med Hyg. 2007;101(10):955-6.

10. Zurolo E, de Groot M, Iyer A, Anink J, van Vliet EA, Heimans JJ, et al. Regulation of Kir4.1 expression in astrocytes and astrocytic tumors: a role for interleukin-1 ß. J Neuroinflammation. 2012;9:280.

11. Coulter DA, Steinhäuser C. Role of astrocytes in epilepsy. Cold Spring Harb Perspect Med. 2015;5(3):a022434.

12. Sharma N, Verma R, Kumawat KL, Basu A, Singh SK. miR-146a suppresses cellular immune response during Japanese encephalitis virus JaOArS982 strain infection in human microglial cells. J Neuroinflammation. 2015;12:30.

13. Ghoshal A, Das S, Ghosh S, Mishra MK, Sharma V, Koli P, et al. Proinflammatory mediators released by activated microglia induces neuronal death in Japanese encephalitis. Glia. 2007;55(5):483-96.

14. Unni SK, Ruzek D, Chhatbar C, Mishra R, Johri MK, Singh SK. Japanese encephalitis virus: from genome to infectome. Microbes Infect. 2011;13(4):312-21. 
15. Kadam SD, Smith-Hicks CL, Smith DR, Worley PF, Comi AM. Functional integration of new neurons into hippocampal networks and poststroke comorbidities following neonatal stroke in mice. Epilepsy Behav. 2010;18(4): 344-57.

16. Yao $Y$, Yang $Y$, He $X$, Wang $X$. miR-16-1 expression, heat shock protein 70 and inflammatory reactions in astrocytes of mice with epilepsy induced by encephalitis B virus infection. Exp Ther Med. 2017;14(1):495-8.

17. Ma J, Zhang T, Jiang L. Japanese encephalitis can trigger anti-N-methyl-Daspartate receptor encephalitis. J Neurol. 2017;264(6):1127-31.

18. Weaver SC, Costa F, Garcia-Blanco MA, Ko Al, Ribeiro GS, Saade G, et al. Zika virus: history, emergence, biology, and prospects for control. Antiviral Res. 2016;130:69-80.

19. Bonello M, Michael BD, Solomon T. Infective causes of epilepsy. Semin Neurol. 2015;35(3):235-44.

20. Singhi P. Infectious causes of seizures and epilepsy in the developing world. Dev Med Child Neurol. 2011;53(7):600-9.

21. Khan E, Barr KL, Farooqi JQ, Prakoso D, Abbas A, Khan ZY, et al. Human West Nile virus disease outbreak in Pakistan, 2015-2016. Front Public Health. 2018;6:20

22. Doron SI, Dashe JF, Adelman LS, Brown WF, Werner BG, Hadley S. Histopathologically proven poliomyelitis with quadriplegia and loss of brainstem function due to West Nile virus infection. Clin Infect Dis. 2003; 37(5):e74-7.

23. Sejvar JJ. West Nile virus infection. Microbiol Spectr. 2016;4(3). https://doi. org/10.1128/microbiolspec.El10-0021-2016

24. Brilla R, Block M, Geremia G, Wichter M. Clinical and neuroradiologic features of 39 consecutive cases of West Nile virus meningoencephalitis. J Neurol Sci. 2004;220(1-2):37-40.

25. Ali M, Safriel Y, Sohi J, Llave A, Weathers S. West Nile virus infection: MR imaging findings in the nervous system. AJNR Am J Neuroradiol. 2005;26(2): 289-97.

26. Petropoulou KA, Gordon SM, Prayson RA, Ruggierri PM. West Nile virus meningoencephalitis: MR imaging findings. AJNR Am J Neuroradiol. 2005; 26(8):1986-95

27. Wang T, Town T, Alexopoulou L, Anderson JF, Fikrig E, Flavell RA. Toll-like receptor 3 mediates West Nile virus entry into the brain causing lethal encephalitis. Nat Med. 2004;10(12):1366-73.

28. Daniels BP, Holman DW, Cruz-Orengo L, Jujjavarapu H, Durrant DM, Klein RS. Viral pathogen-associated molecular patterns regulate blood-brain barrier integrity via competing innate cytokine signals. mBio. 2014;5(5):e01476-14.

29. Samuel MA, Wang H, Siddharthan V, Morrey JD, Diamond MS. Axonal transport mediates West Nile virus entry into the central nervous system and induces acute flaccid paralysis. Proc Natl Acad Sci U S A. 2007;104(43):17140-5.

30. Samuel MA, Diamond MS. Pathogenesis of West Nile virus infection: a balance between virulence, innate and adaptive immunity, and viral evasion. J Virol. 2006;80(19):9349-60.

31. Asadi-Pooya AA. Zika virus-associated seizures. Seizure. 2016;43:13.

32. Moura da Silva AA, Ganz JS, Sousa PD, Doriqui MJ, Ribeiro MR, Branco MD, et al. Early growth and neurologic outcomes of infants with probable congenital Zika virus syndrome. Emerg Infect Dis. 2016;22(11):1953-6.

33. Carvalho M, Miranda-Filho DB, van der Linden V, Sobral PF, Ramos RCF, Rocha MÂW, et al. Sleep EEG patterns in infants with congenital Zika virus syndrome. Clin Neurophysiol. 2017;128(1):204-14.

34. Besnard M, Lastere S, Teissier A, Cao-Lormeau V, Musso D. Evidence of perinatal transmission of Zika virus, French Polynesia, December 2013 and February 2014. Euro Surveill. 2014;19(13):20751.

35. Raymond A, Jakus J. Cerebral infarction and refractory seizures in a neonate with suspected Zika virus infection. Pediatr Infect Dis J. 2018;37(4):e112-e4.

36. Moore CA, Staples JE, Dobyns WB, Pessoa A, Ventura CV, Fonseca EB, et al. Characterizing the pattern of anomalies in congenital Zika syndrome for pediatric clinicians. JAMA Pediatr. 2017;171(3):288-95.

37. Miranda-Filho Dde B, Martelli CM, Ximenes RA, Araújo TV, Rocha MA, Ramos $\mathrm{RC}$, et al. Initial description of the presumed congenital Zika syndrome. Am J Public Health. 2016;106(4):598-600.

38. de Carvalho NS, de Carvalho BF, Dóris B, Silverio Biscaia E, Arias Fugaça C, de Noronha L. Zika virus and pregnancy: an overview. Am J Reprod Immunol. 2017;77(2):e12616.

39. Oliveira-Filho J, Felzemburgh R, Costa F, Nery N, Mattos A, Henriques DF, et al. Seizures as a complication of congenital Zika syndrome in early infancy. Am J Trop Med Hyg. 2018;98(6):1860-2.

40. de Fatima Vasco Aragao M, van der Linden V, Brainer-Lima AM, Coeli RR, Rocha MA, Sobral da Silva P, et al. Clinical features and neuroimaging (CT and MRI) findings in presumed Zika virus related congenital infection and microcephaly: retrospective case series study. BMJ. 2016;353:11901.

41. Passemard S, Kaindl AM, Verloes A. Microcephaly. Handb Clin Neurol. 2013; 111:129-41.

42. Alcantara D, O'Driscoll M. Congenital microcephaly. Am J Med Genet C Semin Med Genet. 2014;166c(2):124-39.

43. Nem de Oliveira Souza I, Frost PS, Franca JV, Nascimento-Viana JB, RLS N, Freitas $L$, et al. Acute and chronic neurological consequences of early-life Zika virus infection in mice. Sci Transl Med. 2018:10(444):eaar2749.

44. Spagnoli C, Falsaperla R, Deolmi M, Corsello G, Pisani F. Symptomatic seizures in preterm newborns: a review on clinical features and prognosis. Ital J Pediatr. 2018;44(1):115.

45. Pancharoen $\mathrm{C}$, Thisyakorn U. Neurological manifestations in dengue patients. Southeast Asian J Trop Med Public Health. 2001;32(2):341-5.

46. Assenza F, Tombini M, Assenza G, Campana C, Benvenga A, Brunelli N, et al. Dengue encephalitis presenting with nonconvulsive status epilepticus: a case report. Clin Neurol Neurosurg. 2016;150:89-91.

47. Sacramento RH, de Melo Braga DN, Sacramento FF, de Carvalho Araujo FM, Lima AA, de Lima Pompeu MM, et al. Death by dengue fever in a Brazilian child: a case report. BMC Res Notes. 2014;7:855.

48. Carod-Artal FJ, Wichmann O, Farrar J, Gascón J. Neurological complications of dengue virus infection. Lancet Neurol. 2013:12(9):906-19.

49. Ramos C, Sánchez G, Pando RH, Baquera J, Hernández D, Mota J, et al. Dengue virus in the brain of a fatal case of hemorrhagic dengue fever. J Neurooncol. 1998;4(4):465-8.

50. Nogueira RM, Filippis AM, Coelho JM, Sequeira PC, Schatzmayr HG, Paiva FG, et al. Dengue virus infection of the central nervous system (CNS): a case report from Brazil. Southeast Asian J Trop Med Public Health. 2002;33(1):68-71.

51. Nimmannitya S, Thisyakorn U, Hemsrichart V. Dengue haemorrhagic fever with unusual manifestations. Southeast Asian J Trop Med Public Health. 1987:18(3):398-406.

52. de Souza KP, Silva EG, de Oliveira Rocha ES, Figueiredo LB, de Almeida-Leite CM, Arantes RM, et al. Nitric oxide synthase expression correlates with death in an experimental mouse model of dengue with CNS involvement. Virol J. 2013:10:267.

53. Puccioni-Sohler M, Rosadas C. Advances and new insights in the neuropathogenesis of dengue infection. Arq Neuropsiquiatr. 2015:73(8): 698-703.

54. Staples JE, Fischer M. Chikungunya virus in the Americas--what a vectorborne pathogen can do. N Engl J Med. 2014;371(10):887-9.

55. Bandeira AC, Campos GS, Sardi SI, Rocha VF, Rocha GC. Neonatal encephalitis due to Chikungunya vertical transmission: first report in Brazil. IDCases. 2016:5:57-9.

56. Samra JA, Hagood NL, Summer A, Medina MT, Holden KR. Clinical features and neurologic complications of children hospitalized with Chikungunya virus in Honduras. J Child Neurol. 2017:32(8):712-6.

57. Singh A, Jain R. Neurological manifestations of Chikungunya in children. Indian Pediatr. 2017:54(3):249.

58. Oliveira R, Barreto FKA, Maia A, Gomes IP, Simião AR, Barbosa RB, et al. Maternal and infant death after probable vertical transmission of chikungunya virus in Brazil - case report. BMC Infect Dis. 2018;18(1):333.

59. Vu DM, Jungkind D, Angelle DL. Chikungunya virus. Clin Lab Med. 2017; 37(2):371-82.

60. Matusali G, Colavita F, Bordi L, Lalle E, Ippolito G, Capobianchi MR, et al. Tropism of the Chikungunya virus. Viruses. 2019;11(2):175.

61. Mahendradas P, Shetty R, Malathi J, Madhavan HN. Chikungunya virus iridocyclitis in Fuchs' heterochromic iridocyclitis. Indian J Ophthalmol. 2010; 58(6):545-7.

62. Hsu CH, Cruz-Lopez F, Torres DV, Perez-Padilla J, Lorenzi OD, Rivera A, et al. Risk factors for hospitalization of patients with chikungunya virus infection at sentinel hospitals in Puerto Rico. PLoS Negl Trop Dis. 2019:13(1): e0007084.

63. Muller DA, Young PR. The flavivirus NS1 protein: molecular and structural biology, immunology, role in pathogenesis and application as a diagnostic biomarker. Antiviral Res. 2013;98(2):192-208.

64. Puerta-Guardo H, Glasner DR, Espinosa DA, Biering SB, Patana M, Ratnasiri K, et al. Flavivirus NS1 triggers tissue-specific vascular endothelial dysfunction reflecting disease tropism. Cell Rep. 2019;26(6):1598-631.

65. Barker-Haliski ML, Loscher W, White HS, Galanopoulou AS. Neuroinflammation in epileptogenesis: insights and translational perspectives from new models of epilepsy. Epilepsia. 2017;58(Suppl 3):39-47. 